\title{
Bu open Objectively measured sedentary time and physical activity in women with fibromyalgia: a cross-sectional study
}

To cite: Ruiz JR, SeguraJiménez V, Ortega FB, et al. Objectively measured sedentary time and physical activity in women with fibromyalgia: a crosssectional study. BMJ Open 2013;3:e002722.

doi:10.1136/bmjopen-2013002722

- Prepublication history for this paper is available online. To view these files please visit the journal online (http://dx.doi.org/10.1136/ bmjopen-2013-002722).

Received 13 February 2013 Revised 12 April 2013 Accepted 15 April 2013

This final article is available for use under the terms of the Creative Commons Attribution Non-Commercial 2.0 Licence; see http://bmjopen.bmj.com

For numbered affiliations see end of article.

Correspondence to Dr Jonatan R Ruiz; ruizj@ugr.es

\section{ABSTRACT}

Objectives: To characterise levels of objectively measured sedentary time and physical activity in women with fibromyalgia.

Design: Cross-sectional study.

Setting: Local Association of Fibromyalgia (Granada, Spain).

Participants: The study comprised 94 women with diagnosed fibromyalgia who did not have other severe somatic or psychiatric disorders, or other diseases that prevent physical loading, able to ambulate and to communicate and capable and willing to provide informed consent.

Primary outcome measures: Sedentary time and physical activity were measured by accelerometry and expressed as time spent in sedentary behaviours, average physical activity intensity (counts/minute) and amount of time (minutes/day) spent in moderate intensity and in moderate-to-vigorous-intensity physical activity (MVPA).

Results: The proportion of women meeting the physical activity recommendations of $30 \mathrm{~min} /$ day of MVPA on 5 or more days a week was $60.6 \%$. Women spent, on average, $71 \%$ of their waking time (approximately $10 \mathrm{~h} /$ day) in sedentary behaviours. Both sedentary behaviour and physical activity levels were similar across age groups, waist circumference and percentage body fat categories, years since clinical diagnosis, marital status, educational level and occupational status, regardless of the severity of the disease (all $p>0.1$ ). Time spent on moderateintensity physical activity and MVPA was, however, lower in those with greater body mass index (BMI) (-6.6 min and -7 min, respectively, per BMI category increase, $<25,25-30,>30 \mathrm{~kg} / \mathrm{m}^{2} ; \mathrm{p}$ values for trend were 0.056 and 0.051 , respectively). Women spent, on average, 10 min less on MVPA $(p<0.001)$ and 22 min less on sedentary behaviours during weekends compared with weekdays $(p=0.051)$.

Conclusions: These data provide an objective measure of the amount of time spent on sedentary activities and on physical activity in women with fibromyalgia.

\section{ARTICLE SUMMARY}

Article focus

- To characterise the levels of objectively measured sedentary time and physical activity (using accelerometry) in women with fibromyalgia.

- To provide estimates of the adherence to recommended levels of physical activity assessed by accelerometry (30 min of moderate-to-vigorousintensity physical activity on 5 of 7 days).

\section{Key messages}

- Over $60 \%$ of women with fibromyalgia meet the physical activity recommendations, that is $30 \mathrm{~min} /$ day of moderate-to-vigorous-intensity physical activity on 5 or more days a week.

- These women spent about $71 \%$ (approximately $10 \mathrm{~h} /$ day) of their waking time on activities that expend little energy.

- Women with fibromyalgia spent, on average, $10 \mathrm{~min}$ less of moderate-to-vigorous-intensity physical activity and 22 min less of sedentary behaviours during weekends compared with weekdays.

Strengths and limitations of this study

- Strict standardisation of the methodology used to measure physical activity and the fact that all women were compliant with the measurement procedures is one of its strengths.

- All women had 7 valid days with at least $10 \mathrm{~h}$ of registered time during waking hours.

- To avoid any kind of immediate reactivity, we removed from the analysis the first day of monitoring.

- The cross-sectional design of our study, however, does not allow us to establish any causal relationships. The sample is one of convenience, which includes the known limitations of all non-probability samples.

- The accelerometer underestimates physical activities that involve upper body movement, as well as those with minimal vertical displacement such as cycling, water-based activities such as swimming. Moreover, it does not capture well the extra energy cost of load-bearing activities such as walking while carrying a backpack. 


\section{INTRODUCTION}

Fibromyalgia is a pain regulation-related disorder. ${ }^{1}$ Patients usually present an increased sensitivity to painful stimuli (hyperalgesia) and lowered pain threshold (allodynia). In addition to pain, fibromyalgia symptoms typically include severe fatigue, sleep disturbances, paraesthesia of the extremities, depression, anxiety, joint stiffness and memory and cognitive difficulties. ${ }^{1} 2$ Fibromyalgia is becoming a common syndrome in Western European countries, and estimates indicate a point prevalence of $2.9 \%$, which translates to approximately six million people with fibromyalgia. ${ }^{3}$

There is increasing evidence about the potential benefits of regular physical activity on fibromyalgia-related symptoms, ${ }^{4-7}$ and international organisations support the use of physical activity-based interventions as a complementary tool in the therapeutic armamentarium against fibromyalgia. ${ }^{8}$ Physical inactivity is one of the major public health problems of the 21 st century, ${ }^{9}$ and several longitudinal studies have shown the negative consequences on health through a sedentary lifestyle. ${ }^{10} 11$

The average amount of daily sedentary time as well as physical activity in women with fibromyalgia is unknown, and the available information is mainly questionnaire based. $^{12-16}$ However, physical activities are difficult to recall, quantify and categorise, ${ }^{17}$ and it might be even more complex in people with memory and cognitive difficulties such as fibromyalgia patients. ${ }^{14}$ Given the limitations of self-report methods, accelerometry (ie, movement sensors) has become the method of choice for objectively measuring physical activity in free-living conditions. ${ }^{18}$ To have an objective diagnosis of sedentary time as well as of the physical activity levels in patients with fibromyalgia is in the interest of public health and of clinical interest, and might be informative for developing intervention studies directed towards the promotion of physical activity in women with fibromyalgia. ${ }^{19}$

The purpose of the present study was to characterise the levels of objectively measured (using accelerometry) sedentary time and physical activity among women with fibromyalgia, and to provide estimates of the adherence to recommended levels of physical activity (30 min of moderate-to-vigorous-intensity physical activity (MVPA) on 5 of 7 days). ${ }^{20} 21$

\section{MATERIAL AND METHODS Study participants}

We sent a formal invitation to participate in the study to all members $(n=400)$ of a Local Association of Fibromyalgia (Granada, Spain). A total of 116 patients responded (response rate $29 \%$ ), and gave their written informed consent after receiving detailed information about the aims and study procedures. Participants were included in the study if: (1) they met the diagnosis of fibromyalgia according to the American College of Rheumatology criteria $^{22}$ (widespread pain for more than 3 months, and pain with $4 \mathrm{~kg} / \mathrm{cm}^{2}$ of pressure reported for 11 or more of 18 tender points), (2) did not have other severe somatic or psychiatric disorders, or other diseases that prevent physical loading (answer 'no' to all questions on the Physical Activity Readiness Questionnaire, ${ }^{23} 24$ (3) were able to ambulate and to communicate and (4) were capable and willing to provide informed consent. Men were not included in the study $(n=6)$, and women with incomplete physical activity data $(n=5)$ or technical errors in the instrument $(n=11)$ were excluded. A final sample of 94 women with fibromyalgia participated in the study. Age, weight and height and fibromyalgia severity (assessed by the fibromyalgia impact questionnaire, FIQ) ${ }^{25} 26$ were similar between the included and excluded participants (all $\mathrm{p}>0.1)$. The study protocol was reviewed and approved by the Ethics Committee of the Hospital Virgen de las Nieves (Granada, Spain). The STROBE guidelines were followed during the course of the research. ${ }^{27}$

\section{Measurements}

Women were interviewed in the Association of Fibromyalgia (Granada, Spain). They were asked to wear an accelerometer (Actigraph GT1M, Pensacola, Florida, USA) for nine consecutive days starting the same day they received the monitor. The accelerometer was carried over the whole day $(24 \mathrm{~h})$ except during water-based activities such as bathing or swimming. Accelerometers were initialised as described by the manufacturer, and data were recorded in $5 \mathrm{~s}$ epochs. Women wore the device on the lower back, secured with an elastic belt, underneath clothing, near to the centre of gravity. The data were downloaded onto a computer using the manufacturer software. Data reduction, cleaning and analyses were performed using the MAHUffe program (see http://www. mrc-epid.cam.ac.uk/Research/Programmes/Programme_ 5/InDepth/Programme\%205_Downloads.html).

Monitor wearing time was calculated by subtracting the sleeping reported time (recorded through a diary) from the total registered time for the entire day (ie, $1440 \mathrm{~min}$ ). Bouts of 60 continuous minutes of 0 activity intensity counts were also excluded from the analysis, considering these periods as non-wearing time. ${ }^{28}$ There was no allowance for any minute with counts between 0 and 100 in the non-wear periods. A recording of more than 20000 counts $/ \mathrm{min}(\mathrm{cpm})$ was considered as a potential malfunction of the accelerometer and the value was excluded from the analyses. ${ }^{28} 29$ The first and last days of recording were not included in the analysis. A total of 7 days (full week) of recording with a minimum of 10 or more hours of registration per day was necessary to be included in the study analysis.

Sedentary time was estimated as the amount of time accumulated below $100 \mathrm{cpm}$ during periods of wear time. ${ }^{30}$ Time spent being sedentary was expressed as total duration (hours/day). Physical activity levels were estimated as follows: (1) average physical activity intensity was expressed as mean cpm, and is a measure of overall physical activity. We calculated mean cpm as the 
sum of total counts per day divided by the number of minutes of wear time in that day, finally calculating the average of all valid days $(n=7)$. (2) Time engaged in moderate physical activity. We calculated the time engaged in moderate-intensity physical activity based on a standardised cut-off of $1952-5724 \mathrm{cpm},{ }^{29} 31$ where $1952 \mathrm{cpm}$ corresponds to walking at $4 \mathrm{~km} / \mathrm{h}^{31}$ (3) We also calculated the time engaged in MVPA as the amount of time accumulated $\geq 1952 \mathrm{cpm}$. Sedentary time, as well as the study physical activity variables, was calculated for weekdays and weekends. We calculated the proportion of women meeting the physical activity recommendations, that is, $30 \mathrm{~min} /$ day of MVPA at least 5 of 7 days. $^{2021}$

Weight and height were measured following standard procedures with a scale (InBody R20 Biospace, Gateshead, UK) and a stadiometer (Seca 22, Hamburg, Germany), respectively, and body mass index (BMI, weight in $\mathrm{kg} / \mathrm{m}^{2}$ ) was calculated. Percentage body fat was measured with bioelectrical impedance analysis (InBody R20; Biospace, Gateshead, UK). Waist circumference was measured at the level of the umbilicus with an anthropometric unelastic tape (Harpenden anthropometric tape, Holtain Ltd). Weight status groups were based on standard clinical definitions for BMI (normal weight $18.5-24.9 \mathrm{~kg} / \mathrm{m}^{2}$, overweight $25.0-29.9 \mathrm{~kg} / \mathrm{m}^{2}$, obese $30.0 \mathrm{~kg} / \mathrm{m}^{2}$ or higher); percentage body fat (normal $<30 \%$; obese $\geq 30 \%$ ) and waist circumference (normal $\leq 80.0 \mathrm{~cm}$; abdominal obesity $>80 \mathrm{~cm}$ ). One woman had a BMI below $18.5 \mathrm{~kg} / \mathrm{m}^{2}\left(18 \mathrm{~kg} / \mathrm{m}^{2}\right)$ and was included in the normal weight group.

Fibromyalgia severity was assessed with the FIQ. ${ }^{25} 26$ FIQ is composed of 10 subscales: physical impairment, overall well-being, work missed, job difficulty, pain, fatigue, morning tiredness, stiffness, anxiety and depression. The score of each subscale was standardised from 0 to 10 . We summed the score of all items, so that the total score ranged from 0 to 100 , with a higher score indicating greater severity. Women were categorised into two groups based on the FIQ total score as FIQ $<70$ and FIQ $\geq 70$. These thresholds correspond to having moderate or severe fibromyalgia, respectively. ${ }^{32}$

\section{Statistical analysis}

All statistical analyses were performed with PASW (Predictive Analytics SoftWare, V.18.0 SPSS Inc, Chicago, Illinois, USA), and the level of significance was set at $\alpha=0.05$. Physical activity and sedentary outcome variables were logarithmically transformed to obtain a normal distribution.

We calculated the estimated means of sedentary time, average physical activity intensity, moderate physical activity and MVPA by age group, BMI and waist circumference categories, years since clinical diagnosis, fibromyalgia severity, marital status, educational level and occupational status, after adjusting for registered time. Linear regression analysis was conducted to examine the association of sedentary time, average physical activity intensity, moderate-intensity physical activity and MVPA (inserted as dependent variables) with age group, BMI, waist circumference and percentage body fat categories, years since clinical diagnosis, fibromyalgia severity and educational level (inserted as independent variables). Independent variables were inserted as ordinal variables. As marital status and occupational status categories were not ordinal variables, we conducted one-way analysis of covariance to determine mean differences in sedentary time and physical activity levels among marital status and occupational status categories. Separate analyses were conducted for each dependent and independent variable. Registered time was entered as a confounder in all models. Mean differences of sedentary time, physical activity, moderate physical activity and MVPA levels on weekdays (Monday-Friday) versus the weekend (Saturday and Sunday) were estimated with one-way analysis of variance for repeated measures.

We analysed the association of meeting the physical activity recommendations ( $\geq 30 \mathrm{~min} /$ day of MVPA on 5 of 7 days a week) with age, waist circumference and percentage body fat, years since clinical diagnosis, fibromyalgia severity, marital status, educational level and using binary logistic regression analysis. Multinomial regression analysis was conducted to examine the association of meeting the physical activity recommendations with BMI and occupational status categories.

\section{RESULTS}

All participants had 7 valid days of registration. Mean registered time during waking time was $842 \pm 108 \mathrm{~min} /$ day $(\sim 14 \pm 1.8 \mathrm{~h})$. There was no significant association of sedentary time and physical activity with age group, waist circumference and percentage body fat categories, years since clinical diagnosis, fibromyalgia severity, marital status, educational level and occupational status (all $\mathrm{p}>0.1$, table 1). Levels of moderate-intensity physical activity and MVPA were lower in women with greater BMI $(\hat{\beta}=-6.6 \pm 3.4$ and $-7 \pm 3.6$ min, respectively, per BMI category increase (ie, $18.5-24.9 \mathrm{~kg} / \mathrm{m}^{2}, 25-29.9 \mathrm{~kg} / \mathrm{m}^{2}$ and $\geq 30 \mathrm{~kg} / \mathrm{m}^{2}$; $\mathrm{p}$ values for trend were 0.056 and 0.051 , respectively, table 1 ). Mean estimates of sedentary time and physical activity intensity levels were similar in women with FIQ $<70$ compared with those with FIQ $\geq 70$ (all $\mathrm{p}>0.5$, table 1 ). For sensitivity analyses, we explored whether the association between physical activity intensity levels and FIQ differ when a different FIQ threshold $(\mathrm{FIQ} \geq 59)^{33}$ was used, yet the findings persisted (data not shown).

The proportion of women meeting the physical activity recommendations by age group, BMI, waist circumference and percentage body fat categories, years since clinical diagnosis, fibromyalgia severity, marital status, educational level and occupational status is shown in table 2. The proportion of women meeting the physical activity recommendations was $60.6 \% \quad(\mathrm{n}=57,95 \%$ CI $52.5 \%$ to $73.2 \%)$. The OR of meeting the physical 
Table 1 Sedentary time and physical activity levels in women with fibromyalgia, by age group, body mass index, waist circumference and percentage body fat category, years since clinical diagnosis, fibromyalgia impact, marital status, educational level and occupational status*

\begin{tabular}{|c|c|c|c|c|c|c|c|c|c|c|c|c|c|}
\hline & \multirow[b]{2}{*}{$\mathbf{N}$} & \multicolumn{3}{|c|}{$\begin{array}{l}\text { Sedentary } \\
\text { (hours/day) }\end{array}$} & \multicolumn{3}{|c|}{$\begin{array}{l}\text { Average PA } \\
\text { (counts/minutes) }\end{array}$} & \multicolumn{3}{|c|}{$\begin{array}{l}\text { Moderate PA } \\
\text { (minutes/day) }\end{array}$} & \multicolumn{3}{|c|}{$\begin{array}{l}\text { MVPA } \\
\text { (minutes/day) }\end{array}$} \\
\hline & & Mean & \multicolumn{2}{|c|}{$95 \% \mathrm{Cl}$} & Mean & \multicolumn{2}{|c|}{$95 \% \mathrm{Cl}$} & Mean & \multicolumn{2}{|c|}{$95 \% \mathrm{Cl}$} & Mean & \multicolumn{2}{|c|}{$95 \% \mathrm{Cl}$} \\
\hline \multicolumn{14}{|l|}{ Age groups (years) } \\
\hline $18-50$ & 41 & 10.0 & 9.6 & 10.5 & 222 & 196 & 248 & 51 & 43 & 59 & 52 & 44 & 60 \\
\hline $51-75$ & 52 & 9.9 & 9.5 & 10.3 & 219 & 195 & 242 & 50 & 43 & 58 & 52 & 44 & 59 \\
\hline $\mathrm{p}$ Value & & 0.65 & & & 0.86 & & & 0.96 & & & & $0 . \subseteq$ & \\
\hline \multicolumn{14}{|c|}{ Body mass index $†$ category $\left(\mathrm{kg} / \mathrm{m}^{2}\right)$} \\
\hline$<25$ & 29 & 10.3 & 9.7 & 10.8 & 229 & 199 & 260 & 56 & 47 & 65 & 58 & 48 & 67 \\
\hline $25-30$ & 34 & 9.5 & 9.0 & 10.0 & 235 & 207 & 263 & 53 & 44 & 61 & 54 & 45 & 63 \\
\hline$>30$ & 27 & 10.1 & 9.6 & 10.7 & 195 & 162 & 227 & 42 & 32 & 52 & 43 & 33 & 54 \\
\hline$p$ for trend & & 0.63 & & & 0.14 & & & 0.056 & & & & 0.0 & \\
\hline \multicolumn{14}{|c|}{ Waist circumference category (cm) } \\
\hline$\leq 80$ & 44 & 10.2 & 9.7 & 10.6 & 233 & 208 & 257 & 54 & 47 & 62 & 56 & 48 & 64 \\
\hline$>80$ & 46 & 9.7 & 9.3 & 10.2 & 209 & 185 & 234 & 47 & 39 & 54 & 48 & 40 & 56 \\
\hline $\mathrm{p}$ Value & & 0.157 & & & 0.18 & & & 0.155 & & & & & \\
\hline \multicolumn{14}{|l|}{ Body fat (\%) } \\
\hline$<30$ & 13 & 10.6 & 9.8 & 11.4 & 210 & 164 & 256 & 48 & 34 & 63 & 50 & 35 & 65 \\
\hline$\geq 30$ & 76 & 9.8 & 9.5 & 10.2 & 223 & 204 & 242 & 51 & 45 & 57 & 52 & 46 & 58 \\
\hline p Value & & 0.93 & & & 0.60 & & & 0.709 & & & & & \\
\hline \multicolumn{14}{|l|}{ Years since clinical diagnosis } \\
\hline$\leq 5$ & 47 & 9.9 & 9.5 & 10.3 & 224 & 200 & 248 & 53 & 46 & 61 & 54 & 47 & 62 \\
\hline$>5$ & 45 & 9.8 & 9.3 & 10.2 & 219 & 194 & 244 & 49 & 41 & 56 & 50 & 43 & 58 \\
\hline $\mathrm{p}$ Value & & 0.650 & & & 0.76 & & & 0.420 & & & & & \\
\hline \multicolumn{14}{|c|}{ Fibromyalgia severity (score)‡ } \\
\hline$<70$ & 42 & 9.9 & 9.4 & 10.3 & 226 & 200 & 251 & 51 & 43 & 60 & 53 & 45 & 61 \\
\hline$\geq 70$ & 50 & 10.0 & 9.6 & 10.5 & 215 & 191 & 238 & 49 & 42 & 57 & 50 & 43 & 58 \\
\hline $\bar{p}$ Value & & 0.632 & & & 0.54 & & & 0.725 & & & & & \\
\hline \multicolumn{14}{|l|}{ Marital status } \\
\hline Married & 72 & 9.9 & 9.6 & 10.3 & 217 & 198 & 237 & 50 & 43 & 56 & 51 & 44 & 57 \\
\hline Unmarried & 22 & 10.0 & 9.4 & 10.7 & 229 & 194 & 264 & 54 & 43 & 65 & 56 & 44 & 67 \\
\hline $\mathrm{p}$ Value & & 0.710 & & & 0.56 & & & 0.510 & & & & & \\
\hline \multicolumn{14}{|l|}{ Educational level } \\
\hline Below university degree & 71 & 9.9 & 9.6 & 10.3 & 222 & 203 & 242 & 51 & 45 & 57 & 53 & 46 & 59 \\
\hline University degree & 22 & 10.2 & 9.5 & 10.8 & 218 & 182 & 253 & 50 & 39 & 61 & 51 & 40 & 63 \\
\hline p Value & & 0.519 & & & 0.81 & & & 0.791 & & & & & \\
\hline \multicolumn{14}{|l|}{ Occupational status } \\
\hline Working & 29 & 9.8 & 9.3 & 10.3 & 222 & 196 & 247 & 51 & 43 & 59 & 52 & 44 & 60 \\
\hline Unemployed & 41 & 10.1 & 9.6 & 10.7 & 236 & 205 & 266 & 55 & 45 & 64 & 57 & 47 & 66 \\
\hline Retired & 24 & 10.0 & 9.3 & 10.6 & 197 & 163 & 232 & 45 & 34 & 56 & 46 & 35 & 57 \\
\hline $\mathrm{p}$ Value & & 0.619 & & & 0.10 & & & 0.187 & & & & & \\
\hline
\end{tabular}

${ }^{*}$ Estimates and $p$ values were adjusted for registered time.

tWeight $(\mathrm{kg}) /$ height $(\mathrm{m})^{2}$.

$\ddagger$ Assessed with the Fibromyalgia Impact Questionnaire.

Analyses were conducted with physical activity and sedentary outcome variables logarithmically transformed to obtain a normal distribution, yet crude values are presented in the table for easier interpretation.

MVPA, moderate-to-vigorous-intensity physical activity; PA, physical activity.

activity recommendations were lower, yet not reaching statistical significance, in the oldest group (OR 0.542, 95\% CI 0.231 to $1.237, \mathrm{p}=0.160$ ), in those with a high waist circumference (OR $0.556,95 \%$ CI 0.235 to $1.312, \mathrm{p}=0.180$ ) and in those diagnosed with fibromyalgia more than 5 years ago (OR $0.485,95 \%$ CI 0.206 to $1.142, \mathrm{p}=0.098$; table 3 ). The OR of meeting the physical activity recommendations was higher, yet not reaching statistical significance, in the normal-weight $\left(\mathrm{BMI}<25 \mathrm{~kg} / \mathrm{m}^{2}\right)$ and in the overweight
(BMI $=25-30 \mathrm{~kg} / \mathrm{m}^{2}$ ) groups compared with the obese peers (OR 2.046, 95\% CI 0.698 to 5.997, $\mathrm{p}=0.192$; OR $2.252,95 \%$ CI 0.794 to $6.385, \mathrm{p}=0.127$; table 4). Unemployed women also had higher OR of meeting the recommendations (OR 2.545, 95\% CI 0.902 to 7.187, $\mathrm{p}=0.078)$. The OR of meeting the physical activity recommendations was lower in women with FIQ $\geq 70$ (OR 0.690, $95 \%$ CI 0.294 to $1.620, \mathrm{p}=0.395)$. The findings persisted when another suggested FIQ threshold (>59 vs $\geq 59$ ) was 
Table 2 Prevalence of meeting the physical activity recommendations (30 min/day of moderate-to-vigorousintensity physical activity) on at least 5 days/week

\begin{tabular}{|c|c|c|c|c|c|}
\hline \multirow{2}{*}{ Age groups (years) } & \multirow[t]{2}{*}{$\mathbf{N}$} & \multirow[t]{2}{*}{ Per cent } & \multicolumn{2}{|c|}{$95 \% \mathrm{Cl}$} & \multirow[t]{2}{*}{ Frequency } \\
\hline & & & & & \\
\hline $18-50$ & 41 & 68.3 & 51.9 & 81.9 & 28 \\
\hline $51-75$ & 52 & 53.8 & 39.5 & 67.8 & 28 \\
\hline \multicolumn{6}{|c|}{ Body mass index category $\left(\mathrm{kg} / \mathrm{m}^{2}\right)$} \\
\hline$<25$ & 29 & 65.5 & 45.7 & 82.1 & 19 \\
\hline $25-30$ & 34 & 67.6 & 49.5 & 82.6 & 23 \\
\hline$>30$ & 27 & 48.1 & 28.7 & 68.1 & 13 \\
\hline \multicolumn{6}{|c|}{ Waist circumference category $(\mathrm{cm})$} \\
\hline$\leq 80$ & 44 & 68.2 & 52.4 & 81.4 & 30 \\
\hline$>80$ & 46 & 54.3 & 39.0 & 69.1 & 25 \\
\hline \multicolumn{6}{|l|}{ Body fat (\%) } \\
\hline$<30$ & 13 & 61.5 & 31.6 & 86.1 & 8 \\
\hline$\geq 30$ & 76 & 61.8 & 50.0 & 72.8 & 47 \\
\hline \multicolumn{6}{|c|}{ Years since clinical diagnosis } \\
\hline$\leq 5$ & 47 & 70.2 & 55.1 & 82.7 & 33 \\
\hline$>5$ & 45 & 53.3 & 37.9 & 68.3 & 24 \\
\hline \multicolumn{6}{|c|}{ Fibromyalgia severity (score) ${ }^{*}$} \\
\hline$<70$ & 42 & 66.7 & 50.5 & 80.4 & 28 \\
\hline$\geq 70$ & 50 & 58 & 43.2 & 71.8 & 29 \\
\hline \multicolumn{6}{|l|}{ Marital status } \\
\hline Married & 72 & 61.1 & 48.9 & 72.4 & 44 \\
\hline Unmarried & 22 & 59.1 & 36.4 & 79.3 & 13 \\
\hline \multicolumn{6}{|l|}{ Educational level } \\
\hline $\begin{array}{l}\text { Below university } \\
\text { degree }\end{array}$ & 71 & 62.0 & 49.7 & 73.2 & 44 \\
\hline $\begin{array}{l}\text { University } \\
\text { degree }\end{array}$ & 22 & 59.1 & 0.0 & 0.0 & 13 \\
\hline \multicolumn{6}{|l|}{ Occupational status } \\
\hline Working & 29 & 62.1 & 42.3 & 79.3 & 18 \\
\hline Unemployed & 41 & 68.3 & 51.9 & 81.9 & 28 \\
\hline Retired & 24 & 45.8 & 25.6 & 67.2 & 11 \\
\hline All & 94 & 60.6 & 52.5 & 73.2 & 57 \\
\hline
\end{tabular}

${ }^{*}$ Assessed with the Fibromyalgia Impact Questionnaire.
Table 3 OR and $95 \% \mathrm{Cl}$ of meeting the physical activity recommendations (30 $\mathrm{min} /$ day of moderate-to-vigorous-intensity physical activity, 5 of 7 days) by age group, body mass index, waist circumference and percentage body fat category, years since clinical diagnosis, marital status, educational level and occupational status

\begin{tabular}{|c|c|c|c|c|}
\hline & OR & \multicolumn{2}{|c|}{$95 \% \mathrm{Cl}$} & p Value \\
\hline \multicolumn{5}{|l|}{ Age groups (years) } \\
\hline $18-50$ & Ref. & & & \\
\hline $51-75$ & 0.542 & 0.231 & 1.273 & 0.160 \\
\hline \multicolumn{5}{|c|}{ Body mass index category $\left(\mathrm{kg} / \mathrm{m}^{2}\right)$} \\
\hline$>30$ & Ref. & & & \\
\hline 25-30 & 2.252 & 0.794 & 6.385 & 0.127 \\
\hline$<25$ & 2.046 & 0.698 & 5.997 & 0.192 \\
\hline \multicolumn{5}{|c|}{ Waist circumference category $(\mathrm{cm})$} \\
\hline$\leq 80$ & Ref. & & & \\
\hline$>80$ & 0.556 & 0.235 & 1.312 & 0.180 \\
\hline \multicolumn{5}{|l|}{ Body fat category (\%) } \\
\hline$<30$ & Ref. & & & \\
\hline$\geq 30$ & 0.987 & 0.297 & 3.309 & 0.983 \\
\hline \multicolumn{5}{|l|}{ Years since clinical diagnosis } \\
\hline$\leq 5$ & Ref. & & & \\
\hline$>5$ & 0.485 & 0.206 & 1.142 & 0.098 \\
\hline \multicolumn{5}{|c|}{ 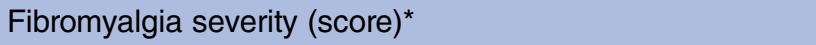 } \\
\hline$<70$ & Ref. & & & \\
\hline$\geq 70$ & 0.690 & 0.294 & 1.620 & 0.395 \\
\hline \multicolumn{5}{|l|}{ Marital status } \\
\hline Married & Ref. & & & \\
\hline Unmarried & 0.919 & 0.347 & 2.432 & 0.865 \\
\hline \multicolumn{5}{|l|}{ Educational level } \\
\hline Below university degree & Ref. & & & \\
\hline University degree & 0.886 & 0.334 & 2.351 & 0.809 \\
\hline \multicolumn{5}{|l|}{ Occupational status } \\
\hline Retired & Ref. & & & \\
\hline Unemployed & 2.545 & 0.902 & 7.187 & 0.078 \\
\hline Working & 1.934 & 0.645 & 5.803 & 0.239 \\
\hline
\end{tabular}

used $^{33}$ (data not shown). Women spent, on average, $71 \%$ of their waking time (approximately $10 \mathrm{~h} /$ day) in sedentary behaviours. The results did not change after adjusting for registered time (data not shown).

Sedentary time and physical activity levels during weekdays (Monday-Friday) and during the weekend (Saturday and Sunday) in women with fibromyalgia are shown in table 4. Mean levels of physical activity were lower during weekends compared with weekdays (mean difference $24 \mathrm{cpm}, 95 \%$ CI 7.8 to $40.2, \mathrm{p}=0.004)$. Likewise, registered time at moderate-intensity physical activity and MVPA was lower during weekends (mean difference $10.5 \mathrm{~min} /$ day, $95 \%$ CI 5.5 to $15.5, \mathrm{p}<0.001$; and $10.6 \mathrm{~min} /$ day, $95 \%$ CI 5.5 to $15.6, \mathrm{p}<0.001)$, respectively). Mean levels of sedentary time were also lower during weekends (mean difference $22.6 \mathrm{~min} /$ day, $95 \%$ CI 0 to $45.3, \mathrm{p}=0.051$ ). Figure 1 shows the sedentary time and physical activity mean time by weekdays and weekend days. 
Table 4 Sedentary time and physical activity levels during weekdays (Monday-Friday) and during weekends (Saturday and Sunday) in women with fibromyalgia

\begin{tabular}{|c|c|c|c|c|c|c|c|}
\hline & \multicolumn{2}{|l|}{ Week } & \multicolumn{2}{|c|}{ Weekend } & \multicolumn{3}{|c|}{ Difference } \\
\hline & Mean & SD & Mean & SD & Mean & $95 \% \mathrm{Cl}$ & p Value \\
\hline Sedentary (hours/day) & 10.0 & 2.2 & 9.6 & 2.5 & 0.4 & 0.0 to 0.8 & 0.051 \\
\hline Average PA (counts/minutes) & 225.1 & 88.5 & 201.0 & 98.0 & 24.0 & 7.8 to 40.2 & 0.004 \\
\hline Moderate PA (minutes/day) & 53.1 & 28.4 & 42.6 & 28.0 & 10.5 & 5.5 to 15.5 & $<0.001$ \\
\hline MVPA (minutes/day) & 54.3 & 29.1 & 43.8 & 29.7 & 10.6 & 5.5 to 15.6 & $<0.001$ \\
\hline
\end{tabular}

Analyses were conducted with physical activity and sedentary outcome variables logarithmically transformed to obtain a normal distribution, yet crude values are presented in the table for easier interpretation.

MVPA, moderate-to-vigorous-intensity physical activity; PA, physical activity.

The present study showed that $60.6 \%$ of women met the recommendation to accumulate 30 or more min/ day of physical activity of MVPA on most days of the week. The variation in meeting the recommendations was not associated with the study demographic factors, and despite the prevalence of meeting the recommendations, tended to be lower in the oldest group. In the overweight group and in those with a higher waist circumference, in those with fibromyalgia being diagnosed more than 5 years ago, and in the retired group, the associations were not statistically significant. Time spent on moderate-intensity physical activity and MVPA, however, tended to be lower in those with greater BMI (-6.6 and $-7 \mathrm{~min}$, respectively, per BMI category increase, $<25,25-30$ and $>30 \mathrm{~kg} / \mathrm{m}^{2}$ ), which concurs with studies in healthy adults. ${ }^{29}$ This may have important health implications since obese female fibromyalgia patients seem to have higher levels of pain, anxiety and depression and a worse quality of life, as well as lower functional capacity than their normal weight peers. ${ }^{34}$

Despite several attempts having been made to objectively quantify sedentary behaviours and physical activity levels in people with fibromyalgia, ${ }^{12} 1^{13} 35-38$ to our knowledge, there are no previous studies showing the prevalence of meeting the physical activity recommendations in women with fibromyalgia, which hamper between-study comparisons. McLoughlin et al ${ }^{13}$ measured physical activity with accelerometry in 26 female fibromyalgia patients aged $42.7 \pm 12$ years, but they did not show the prevalence of meeting the recommendations. They showed, however, that time spent at moderate intensity, using the same intensity threshold as used in the present study, ${ }^{31}$ was $15 \pm 8 \mathrm{~min} /$ day, which is on average $\sim 35$ min lower (using the 51-75 years age group as a reference group) than the time observed in the present study. Kaleth et $a l^{12}$ also measured physical activity with accelerometry in 30 fibromyalgia patients (27 women), but unfortunately, they did not show the physical activity estimates. Kashikar-Zuck $e$ t $a l^{88}$ measured physical activity with accelerometry in a juvenile primary fibromyalgia syndrome group of adolescents and showed that only $23 \%$ achieved $30 \mathrm{~min} /$ day of MVPA, and only one patient achieved the recommended levels of physical activity for their age, that is $60 \mathrm{~min} /$ day of MVPA. ${ }^{20} 21$

Data coming from apparently healthy women showed lower rates of meeting the recommendation than those observed in the present study. ${ }^{28} \quad 29 \quad 39 \quad 40$ Hagstromer et $a l^{29}$ reported that $48 \%$ of a representative
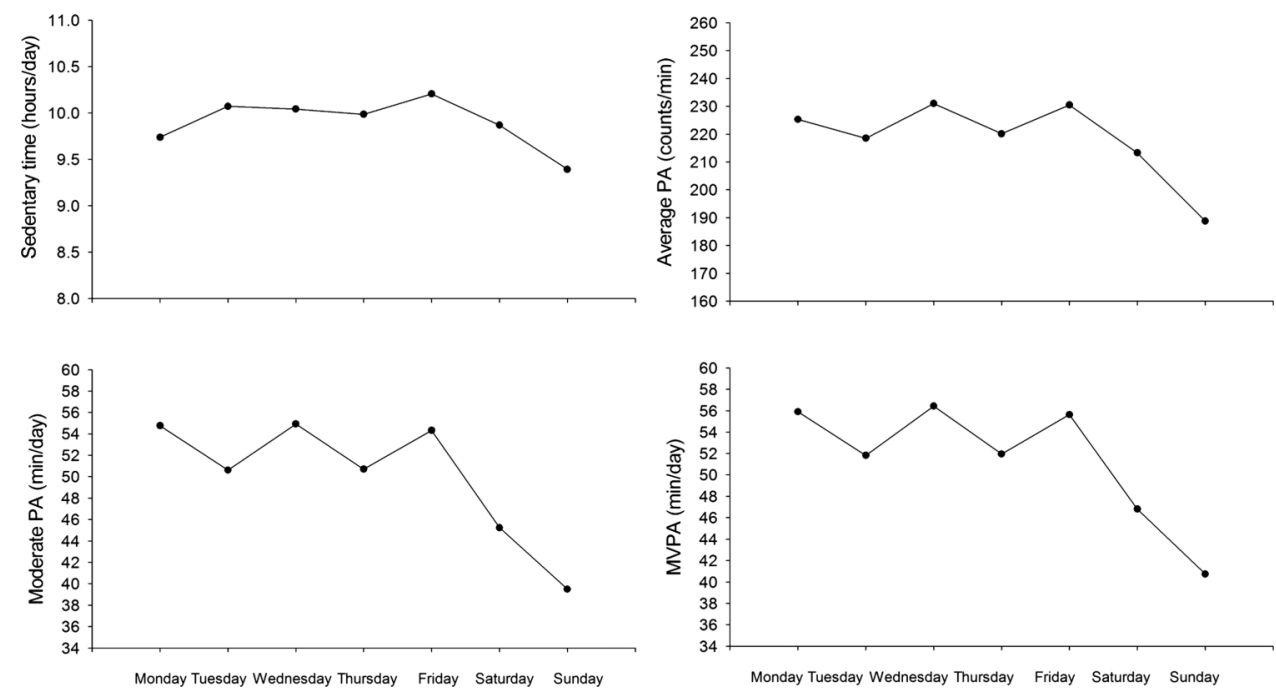

Figure 1 Sedentary time and physical activity (PA) mean time by week and weekend days. 
sample of Swedish women accumulated $30 \mathrm{~min} /$ day of MVPA, and data from the Canadian Health Measures Survey ${ }^{40}$ showed that less than $5 \%$ engaged in $30 \mathrm{~min} /$ day of MVPA on at least 5 of 7 days. Similarly, findings from the National Health and Nutritional Examination Survey (NHANES) 2003-2004 indicated that less than $5 \%$ of a representative sample of women from the $\mathrm{USA}^{28}$ met the physical activity recommendations, and $7 \%$ of US women met the physical activity recommendations in 2005-2006 (NHANES).$^{39}$ Methodological procedures used to measure physical activity, such as the number of valid days included in the analysis and exclusion of the first recording day to avoid reactivity and criteria used to define compliance, may partially explain the observed differences among studies. Although all women in our study had 7 valid days with at least $10 \mathrm{~h}$ of registered time during waking hours, in the other studies participants with 4 valid days were included in the study. Of note is that, for example, the NHANES 2003-2004 ${ }^{28}$ study included participants with just one or more valid days when calculating population adherence estimates. Besides the aforementioned methodological difference, it cannot be denied, however, that cultural differences might also explain the observed discrepancies.

Sedentary behaviours refer to those activities that do not increase resting energy expenditure substantially, that is, no more than 1.5 times the resting energy expenditure. ${ }^{41}$ These activities involve sitting, reclining and lying down, as well as watching television, studying, reading, etc. In the present study, we observed that women spend, on average, $10 \mathrm{~h} /$ day $(\sim 71 \%)$ of their waking time in sedentary activities, which is similar to that observed in Portuguese women, ${ }^{42}$ and slightly higher than in American and Swedish women (about 7-8 h). ${ }^{29}$ McLoughlin et $a l^{13}$ also measured sedentary time with accelerometry, but the data are not comparable with our study because they included sleeping time as a sedentary activity. They reported that women with fibromyalgia spend $1154 \pm 59 \mathrm{~min} /$ day at sedentary behaviours, which, together with the registered time in other physical activity intensities, summed $\sim 1440 \mathrm{~min}$, which is a full day. We observed no association of sedentary time with any of the study demographic factors, which concurs with the Swedish study by Hagstromer et $a l^{29}$ Similarly, women with a higher severity of the disease $(\mathrm{FIQ} \geq 70)$ showed similar sedentary patterns to those with an FIQ $<70$, which concurs with the findings reported by McLoughlin et $a l^{13}$

In our study, women with fibromyalgia spend less time $(\sim 10 \mathrm{~min} /$ day $)$ on MVPA and on sedentary time ( $22 \mathrm{~min} /$ day) during weekends compared with weekdays. These findings are in agreement with the results reported by Cooper et al. ${ }^{43}$ The observed physical activity reduction during weekends could be partially explained by a reduced transport-related physical activity when commuting to or from work, whereas the reduction of sedentary time could be due to a reduced work-related sitting time. More studies quantifying and characterising physical activity and sedentary patterns during weekends and weekdays are needed.

The present study has several limitations. The crosssectional design of our study does not allow us to establish any causal relationship. The sample is one of convenience and includes the known limitations of all non-probability samples, including those of less representativeness and unknown levels of sampling error. Further studies involving randomly recruited patients with fibromyalgia are needed. Of note also is the relatively low response rate $(29 \%)$. We cannot deny that women who agreed to participate in this study are those who are aware of the importance of having an active lifestyle, which may have influenced the results. It should also be mentioned that the accelerometer underestimates physical activities that involve upper body movement, those with minimal vertical displacement such as cycling, water-based activities such as swimming, and it does not capture well the extra-energy cost of loadbearing activities, such as walking while carrying a backpack. Nevertheless, walking is the most prevalent leisuretime physical activity among women with fibromyalgia, ${ }^{15}$ and is most likely the type of activity they do at work and for transportation. We used the same cut-points for all ages and BMI levels as has been carried out in previous studies. $^{28}{ }^{29}$ Use of a single cut-point for all ages and BMI levels may, however, lead to an underestimate of moderate-intensity physical activity for the older and heavier group by not accounting for the decline in exercise capacity with age and weight. We do not present data on vigorous physical activity because the time spent at this intensity ranged from 0 to 2 min (see table 1, subtract moderate intensity to MVPA). On average, $\sim 98 \%$ of the time spent at MVPA is moderate-intensity physical activity. This is consistent with the available clinical knowledge on this population, and concurs with data from apparently healthy women from Sweden. ${ }^{29}$ The observed low levels of vigorous physical activity could also suggest that the cut-point for this intensity was too high, thereby missing many minutes of activity in our population that should have been classified as vigorous physical activity. Unfortunately, we have no data on an age-matched and culturally matched group of healthy women, so direct comparisons cannot be made. McLoughlin et $a l^{13}$ observed that female fibromyalgia patients $(n=26)$ were less active than a group of healthy women $(n=26)$; yet the healthy group was younger and had a higher level of education than the patient-group. Despite the number of participants in the present study being relatively small, to date, this is the largest series described in adults. We do not know whether these findings apply to men, and therefore future studies should quantify both sedentary time and physical activity in this group of patients. $\mathrm{We}^{44}$ and others ${ }^{45}$ observed gender differences in patients with fibromyalgia; therefore, studies focused on examining gender differences in sedentary time and physical activity will provide further 
insights on whether preventive and interventions strategies should be gender-specific.

One of the strengths of the present study, however, was the strict standardisation of methodology used to measure physical activity, and the fact that all women were compliant with the measurements procedures. All women had 7 valid days with at least $10 \mathrm{~h}$ of registered time during waking hours. Indeed, the mean daily accelerometer wear time was $14 \pm 1.8 \mathrm{~h} /$ day. We do not know whether women modified their habitual sedentary behaviour or physical activity during the days they were monitored despite their being advised to keep on with their normal life. To avoid any kind of immediate reactivity, we removed from the analysis the first day of monitoring.

Modifiable lifestyle factors, such as physical activity, may have great potential as a public health instrument to prevent and contribute to the treatment of fibromyalgia. Longitudinal studies are also needed to further understand the predictive value of sedentary behaviours and physical activity over the course of the disease, and whether preventive strategies should start at the early stages of disease development. To have an objective estimate of the patient's sedentary behaviour as well as the engagement in physical activity could be used as a potential tool to increase the effectiveness of treatment approaches as well as to reduce disability and enhance the quality of life in people with fibromyalgia. Indeed, Fontaine et $a l^{46}$ observed that accumulating $30 \mathrm{~min}$ of moderate-intensity physical activity throughout the day produces clinically relevant changes in perceived physical function and pain in previously minimally active adults with fibromyalgia.

In summary, these data provide an objective measure of the amount of time spent on sedentary activities and on physical activity in women with fibromyalgia. These estimates can be used for comparisons with other rheumatological diseases, as baseline reference levels for monitoring, and to assess the effectiveness of intervention strategies promoting physical activity in women with fibromyalgia.

\section{Author affiliations}

${ }^{1}$ PROFITH "PROmoting FITness and Health through physical activity" Research Group, Faculty of Sport Sciences, Department of Physical Education and Sports, University of Granada, Granada, Spain

${ }^{2}$ Department of Physical Education and Sport, Faculty of Sport Sciences, University of Granada, Granada, Spain

${ }^{3}$ Department of Physiology, School of Pharmacy and Institute of Nutrition and Food Technology, University of Granada, Granada, Spain

${ }^{4}$ Department of Physical Education, School of Education, University of Cadiz, Cadiz, Spain

${ }^{5}$ Department of Biostatistics, School of Medicine, University of Granada, Granada, Spain

${ }^{6}$ Deparment of Sports and Informatics, Section of Physical Education and Sports, Faculty of Sport, University Pablo de Olavide, Seville, Spain

Acknowledgements The authors gratefully acknowledge all women for their collaboration. We also acknowledge the AGRAFIM (association of fibromyalgia from Granada, southern Spain) members involved in the fieldwork for their effort and great enthusiasm.

Contributors JRR participated in the conception and design of the study, data collection, statistical analysis and interpretation of data, and drafting of the article. VS-J, FBO, ICA-G and DC-M participated in data collection, interpretation of data and revising the article critically for important intellectual content. VAA, AC-B and MD-F participated in the conception and design of the study, data collection, interpretation of data and in revising the article critically for important intellectual content. PF participated in statistical analysis, interpretation of data and revising the article critically for important intellectual content. DM-I participated in interpretation of data, and revising the article critically for important intellectual content. All authors have read and approved the final manuscript.

Funding This study was supported by the Consejeria de Turismo, Comercio y Deporte (CTCD-201000019242-TRA), the Spanish Ministry of Science and Innovation (I+D+I DEP2010-15639, grants: BES-2009-013442, BES-2011-047133, RYC-2010-05957, RYC-2011-09011), the Spanish Ministry of Education (AP-2009-3173 and AP2010-0963), Granada Research of Excelence Initiative on Biohealth (GREIB), Campus BioTic, University of Granada, Spain and the European University of Madrid, Escuela de Estudios Universitarios Real Madrid (2010/04RM).

Competing interests None.

Ethics approval Hospital Virgen de las Nieves (Granada, Spain).

Provenance and peer review Not commissioned; externally peer reviewed.

Data sharing statement Extra data are available by emailing at ruizj@ugr.es.

\section{REFERENCES}

1. Bennett RM. Clinical manifestations and diagnosis of fibromyalgia. Rheum Dis Clin North Am 2009;35:215-32.

2. Wilson HD, Robinson JP, Turk DC. Toward the identification of symptom patterns in people with fibromyalgia. Arthritis Rheum 2009;61:527-34.

3. Branco JC, Bannwarth B, Failde I, et al. Prevalence of fibromyalgia: a survey in five European countries. Semin Arthritis Rheum 2010;39:448-53.

4. Thomas EN, Blotman F. Aerobic exercise in fibromyalgia: a practical review. Rheumatol Int 2010;30:1143-50.

5. Busch AJ, Webber SC, Brachaniec M, et al. Exercise therapy for fibromyalgia. Curr Pain Headache Rep 2011;15:358-67.

6. Kelley GA, Kelley KS, Hootman JM, et al. Exercise and global well-being in community-dwelling adults with fibromyalgia: a systematic review with meta-analysis. BMC Public Health 2010;10:198.

7. Hauser W, Klose P, Langhorst $\mathrm{J}$, et al. Efficacy of different types of aerobic exercise in fibromyalgia syndrome: a systematic review and meta-analysis of randomised controlled trials. Arthritis Res Ther 2010;12:R79.

8. Brosseau L, Wells GA, Tugwell P, et al. Ottawa Panel evidence-based clinical practice guidelines for aerobic fitness exercises in the management of fibromyalgia: part 1. Phys Ther 2008;88:857-71.

9. Blair SN. Physical inactivity: the biggest public health problem of the 21st century. Br J Sports Med 2009;43:1-2.

10. Matthews CE, George SM, Moore SC, et al. Amount of time spent in sedentary behaviors and cause-specific mortality in US adults. $A m J$ Clin Nutr 2012;95:437-45.

11. Thorp AA, Owen N, Neuhaus M, et al. Sedentary behaviors and subsequent health outcomes in adults a systematic review of longitudinal studies, 1996-2011. Am J Prev Med 2011;41:207-15.

12. Kaleth AS, Ang DC, Chakr R, et al. Validity and reliability of community health activities model program for seniors and short-form international physical activity questionnaire as physical activity assessment tools in patients with fibromyalgia. Disabil Rehabil 2010;32:353-9.

13. McLoughlin MJ, Colbert LH, Stegner AJ, et al. Are women with fibromyalgia less physically active than healthy women? Med Sci Sports Exerc 2011;43:905-12.

14. Munguia-Izquierdo D, Legaz-Arrese A, Mannerkorpi K. Transcultural adaptation and psychometric properties of a Spanish-language version of physical activity instruments for patients with fibromyalgia. Arch Phys Med Rehabil 2011;92:284-94.

15. Mannerkorpi K, Hernelid C. Leisure time physical activity instrument and physical activity at home and work instrument. Development, face validity, construct validity and test-retest reliability for subjects with fibromyalgia. Disabil Rehabil 2005;27:695-701.

16. Mork PJ, Vasseljen O, Nilsen TI. Association between physical exercise, body mass index, and risk of fibromyalgia: longitudinal data from the Norwegian Nord-Trondelag Health Study. Arthritis Care Res (Hoboken) 2010;62:611-17. 
17. Van Poppel MN, Chinapaw MJ, Mokkink LB, et al. Physical activity questionnaires for adults: a systematic review of measurement properties. Sports Med 2010;40:565-600.

18. Freedson P, Bowles HR, Troiano R, et al. Assessment of physical activity using wearable monitors: recommendations for monitor calibration and use in the field. Med Sci Sports Exerc 2012;44 (1 Suppl 1):S1-4

19. Carbonell-Baeza A, Ruiz JR, Aparicio VA, et al. Land- and water-based exercise intervention in women with fibromyalgia: the al-Andalus physical activity randomised control trial. BMC Musculoskelet Disord 2012;13:18.

20. WHO. Global Recommendations on physical activity for health Geneva, Switzerland: World Health Organ Publications, 2010.

21. U.S. Department of health and human services. Physical activity and health: a report of the surgeon general. Atlanta GA: U.S. Department of Health and Human Services, Centres for Disease Control and Prevention, National Centre for Chronic Disease Prevention and Health Promotion. http://www.cdc.gov/nccdphp/sgr/ sgr.htm (accessed 11 Mar 2008)

22. Wolfe F, Smythe HA, Yunus MB, et al. The American College of Rheumatology 1990 Criteria for the Classification of Fibromyalgia. Report of the Multicenter Criteria Committee. Arthritis Rheum 1990;33:160-72

23. Cardinal BJ, Esters J, Cardinal MK. Evaluation of the revised physical activity readiness questionnaire in older adults. Med Sci Sports Exerc 1996;28:468-72.

24. Rodriguez FA. Spanish version of the Physical Activity Readiness Questionnaire (C-AAF/rPAR-Q). Arch Med Deporte 1996;13:63-8

25. Rivera J, Gonzalez T. The Fibromyalgia Impact Questionnaire: a validated Spanish version to assess the health status in women with fibromyalgia. Clin Exp Rheumatol 2004;22:554-60.

26. Burckhardt CS, Clark SR, Bennett RM. The fibromyalgia impact questionnaire: development and validation. J Rheumatol 1991;18:728-33.

27. Von Elm E, Altman DG, Egger M, et al. The Strengthening the Reporting of Observational Studies in Epidemiology (STROBE) statement: guidelines for reporting observational studies. Ann Intern Med 2007;147:573-7.

28. Troiano RP, Berrigan D, Dodd KW, et al. Physical activity in the United States measured by accelerometer. Med Sci Sports Exerc 2008;40:181-8.

29. Hagstromer M, Oja P, Sjostrom M. Physical activity and inactivity in an adult population assessed by accelerometry. Med Sci Sports Exerc 2007;39:1502-8.

30. Matthews CE, Chen KY, Freedson PS, et al. Amount of time spent in sedentary behaviors in the United States, 2003-2004. Am J Epidemiol 2008;167:875-81.
31. Freedson PS, Melanson E, Sirard J. Calibration of the Computer Science and Applications, Inc. accelerometer. Med Sci Sports Exerc 1998;30:777-81.

32. Bennett R. The Fibromyalgia Impact Questionnaire (FIQ): a review of its development, current version, operating characteristics and uses. Clin Exp Rheumatol 2005;23(5 Suppl 39):S154-62.

33. Bennett RM, Bushmakin AG, Cappelleri JC, et al. Minimal clinically important difference in the fibromyalgia impact questionnaire. J Rheumatol 2009;36:1304-11.

34. Aparicio VA, Ortega FB, Carbonell-Baeza A, et al. Relationship of weight status with mental and physical health in female fibromyalgia patients. Obes Facts 2011;4:443-8.

35. Kop WJ, Lyden A, Berlin AA, et al. Ambulatory monitoring of physical activity and symptoms in fibromyalgia and chronic fatigue syndrome. Arthritis Rheum 2005;52:296-303.

36. Korszun A, Young EA, Engleberg NC, et al. Use of actigraphy for monitoring sleep and activity levels in patients with fibromyalgia and depression. J Psychosom Res 2002;52:439-43.

37. Ellingson LD, Shields MR, Stegner AJ, et al. Physical activity, sustained sedentary behavior, and pain modulation in women with fibromyalgia. J Pain 2012;13:195-206.

38. Kashikar-Zuck S, Flowers SR, Verkamp E, et al. Actigraphy-based physical activity monitoring in adolescents with juvenile primary fibromyalgia syndrome. J Pain 2010;11:885-93.

39. Tucker JM, Welk GJ, Beyler NK. Physical activity in U.S.: adults compliance with the Physical Activity Guidelines for Americans. Am J Prev Med 2011;40:454-61.

40. Colley RC, Garriguet D, Janssen I, et al. Physical activity of Canadian adults: accelerometer results from the 2007 to 2009 Canadian Health Measures Survey. 2011;22:7-14.

41. Pate RR, O'Neill JR, Lobelo F. The evolving definition of "sedentary". Exerc Sport Sci Rev 2008;36:173-8.

42. Baptista F, Santos DA, Silva AM, et al. Prevalence of the Portuguese population attaining sufficient physical activity. Med Sci Sports Exerc 2012;44:466-73.

43. Cooper AR, Page A, Fox KR, et al. Physical activity patterns in normal, overweight and obese individuals using minute-by-minute accelerometry. Eur J Clin Nutr 2000;54:887-94.

44. Aparicio VA, Ortega FB, Carbonell-Baeza A, et al. Are there gender differences in quality of life and fibromyalgia symptomatology?. Am J Mens Health 2012;6:314-9.

45. Miro E, Diener FN, Martinez MP, et al. Fibromyalgia in men and women: comparison of the main clinical symptoms. Psicothema 2012;24:10-15.

46. Fontaine KR, Conn L, Clauw DJ. Effects of lifestyle physical activity on perceived symptoms and physical function in adults with fibromyalgia: results of a randomized trial. Arthritis Res Ther 2010;12:R55. 